\title{
Evaluation of R\&D effectiveness of small and medium-sized enterprises based on the DEA model
}

\author{
Yu YuanYuan ${ }^{1,2}$ \\ 1. School of management,Jiang Su university,Zhen Jiang,Jiang Su,212013,China. \\ 2. School of business, Jiang Nan University,Wuxi,Jiang Su,214122,China. \\ Xuyuan1530@sina.com
}

Keywords: R\&D,DEA,Validity,Scale efficiency

\begin{abstract}
In the era of knowledge economy, in order to maintain their survival and development, enterprises should continue to carry out technological innovation. Enterprises need to enhance the independent innovation based on $\mathrm{R} \& \mathrm{D}$ activities. The scale and strength of research and development investment is important index to measure the enterprise' innovation ability , and is one of the main ways to form the enterprises' core competitiveness. Then what is the reality of the small and medium-sized enterprise'R\&D activities and performance? Is the small and medium-sized enterprise'research and development effective? Can it drive the transformation of SMEs upgrade? This article surveyed 31 Listed Small and medium-sized enterprise as sample, used data envelopment analysis ( DEA ) to analyze the listed SMEs' R\&D relative efficiency and scale benefits through specific indicators, get a meaning conclusions for reference.
\end{abstract}

\section{Introduction}

That economic development of China and foreign countries has indicated that the technological innovation of small and medium-sized enterprises has become an important support for many countries' economic growth. The technology innovation is the key factor for the survival and development of SMEs in China except the system factors. The technological innovation of small and medium-sized enterprises originates with the technology, product research and development related to innovation and development activities, becomes the key factor of the success of SMEs. But the effectiveness of enterprise' $\mathrm{R} \& \mathrm{D}$ investment is lack of science and consistent empirical support. Some studies show that there is a significant correlation between the performance of the company and R \& D investment. For example, Cheng et al(2006) found that there was a positive relationship between $\mathrm{R} \& \mathrm{D}$ strength and profit rate of main business ${ }^{[1]}$. Yu (2009) found that it was not a simple linear relation between $\mathrm{R} \& \mathrm{D}$ investment and output growth in China, $\mathrm{R}$ \& $\mathrm{D}$ investment largely promote the output of the enterprises' growth ${ }^{[2]}$. Jie\&Tang (2011)found that enterprise $\mathrm{R} \& \mathrm{D}$ input had positive effect on enterprise performance, and relied on the external environment and internal management mechanism ${ }^{[3]}$. But there are other studies found that R \& D investment had no even counterproductive effect on corporate performance. For example, Yu(2006) drew the conclusion that the performance of $R \& D$ input in china relatively poor through analyzing the China's R\&D expenditure performance from 1995 to $2003^{[4]}$. Liang\&Zhang (2006) found that there was no significant correlation between R\&D input intensity and the rate of return on total assets through the empirical analysis of 96 high-tech enterprises ${ }^{[5]}$.Zhou\&Lu(2002) found no significant correlation between $\mathrm{R} \& \mathrm{D}$ investment and enterprise performance by conducting a questionnaire to survey 1162 science and technology enterprises in Zhejiang Province ${ }^{[6]}$. Zhu\&Lun(2004) found that the relationship between coefficient of competitive advantage of high-tech enterprises and the input of technology capital and human resource was not only weak but also a negative relationship ${ }^{[7]}$. You (2010) found that R\&D investment had no effect on performance. It proved that the current $R \& D$ activities of small and medium-sized enterprises of our country failed to provide the support for the sustainable development of the enterprises ${ }^{[8]}$.

From the current research results of domestic R\&D investment' effectiveness, although there has been some positive results, but researches mainly focus on the macro level or large enterprises, little 
has been seen the plenty of small and medium enterprises. It is not systematic. And there are no related results research of both the size of the enterprise research and $R \& D$ effectiveness at the same time. And analysis of data is from 2006 and earlier, before the new accounting standards issued in 2006, the listing Corporation in China R \& D expenditure disclosure did not been made any requirements, so the $\mathrm{R} \& \mathrm{D}$ information disclosure of listing Corporation is a voluntary disclosure behavior. It is not standardized. How are R \& D activities and performance of small and medium-sized enterprises in reality? Is it effective of $\mathrm{R} \& \mathrm{D}$ investment of small and medium enterprises? Can R \& D investment transform and upgrade the SMEs? In this paper, we analyze the $R \& D$ investment and enterprise scale in the small and medium-sized enterprise' effecting on R\&D effectiveness after 2006.It has the practical significance, also provide guidance for small and medium-sized enterprises to investment in research and development and practice the technology innovation.

\section{The construction of sample and the index system}

\subsection{Data Envelopment Analysis}

The method of data envelopment analysis (DEA) is a linear programming technique, based on relative efficiency. It is a nonparametric statistical method to evaluate the same type of multiple input and output decision making units is effective or not. It is proposed by famous strategist Charnes and Cooper et al in 1978. The DEA method uses the evaluation unit of input, output data to make a comprehensive evaluation directly. It can obtain the total quantitative index of effectiveness about evaluation units and determine the effective (i.e. the highest relative efficiency) units, point out the other units' non of effective' reason and degree quantitatively. Because the DEA method focuses on individuals rather than the average, it has a unique advantage to investigate the differences on individual decision making unit (especially Decision Making Unit, DMU) on performance and relative efficiency. CCR model and BCC model are the commonly used DEA model.

\section{2 sample and selection}

We randomly selected 31 Listed SMEs as the analysis sample. The 31 small and medium enterprises are 31 DMUs. Consider the availability, continuity and comprehensive data analysis, we used the panel data of 2007, 2008, 2009, 2010 of the small and medium-sized enterprises in sample to measure the relative efficiency of investment in research and development of small and medium-sized enterprises, Investigate the overall efficiency, pure technical efficiency and scale efficiency and changes in the returns to scale.

\subsection{The construction of index system}

\subsubsection{The input indexes}

Input indicators are $\mathrm{R} \& \mathrm{D}$ funding $\left(\mathrm{x}_{1}\right), \mathrm{R} \& \mathrm{D}$ personnel $\left(\mathrm{x}_{2}\right)$. R \& $\mathrm{D}$ funding reflects the enterprise's R \& D investment scale, R \& D personnel reflects the enterprises in the development of human resources investment.

\subsubsection{The output indexes}

The output indexes are total profit $\left(\mathrm{y}_{1}\right)$, operating income growth rate $\left(\mathrm{y}_{2}\right)$, inventory turnover rate $\left(y_{3}\right)$. Total profit reflects the profitability of the enterprises, operating income growth rate reflects the business development capacity, inventory turnover rate reflects the operating efficiency.

In the original data about input and output, there is a negative number because of the index characters, such as the gross profit, operating income growth rate. So we normalized the original data. All the data values in the interval $[0.1,1]$ range after normalized. The normalized formula is:

$$
x_{i j}{ }^{\prime}=0.1+\frac{x_{i j}-\min x_{i j}}{\max x_{i j}-\min x_{i j}} \times 0.9
$$

After normalized, the frontier of DMU only translates and occurs scaling.the overall shape keep invariant. Namely the relative relationship among DMU does not change, so it has no influence on the result of evaluation. 
The original sample data of this paper mainly come from the annual report of the small and medium enterprises released.

\section{The empirical results analysis}

We combined constant returns to scale ( $C^{2} R$ model) and variable returns to scale model ( $\mathrm{BC}^{2}$ model), calculated with the DEAP2.1 software, obtained the 31 investment in research and development of small and medium-sized enterprises’ relative efficiency.

\section{1 the relative efficiency analysis}

The R \& D efficiency of the enterprises is valued by using the technical efficiency, pure technical efficiency and scale efficiency. Generally speaking, the overall technical efficiency of 1 represents the most efficient units, namely the efficiency of research and development is at its best; we can observe whether the R \& D expenses and R \& D personnel input is valid from pure technical efficiency. The larger the value trend, the more efficiently the input resources used; Scale efficiency can be divided for returns to scale increasing, returns to scale constant and returns to scale decreasing.

5 enterprises reach overall technical efficiency, accounting for $16.1 \%$ of the total number of samples. The average value of the overall technical efficiency is 0.573 .14 enterprises are higher than the average value, accounting for $46.2 \%$ of the total number of samples.17 enterprises are lower than the average value, accounting for $54.8 \%$ of the total number of samples. If the scale efficiency is effective, the technical efficiency is effective too. That is in the constant returns to scale region ,small and medium enterprises can realize the integrated technology effectively; in the region of increasing returns to scale, overall technical efficiency is invalid; in the region of decreasing returns to scale, overall technical efficiency is invalid too.

13 enterprises reach pure technical efficiency (i.e. the efficiency of R \& D), accounting for $41.9 \%$ of the total number of samples. 18 enterprises are invalid in pure technical efficiency, accounting for $58.1 \%$ of the total number of samples. The average value of pure technical efficiency is 0.691 .15 enterprises are higher than the average value, accounting for $48.4 \%$ of the total number of samples. 16 enterprises are lower than the average value, accounting for $51.6 \%$ of the total number of samples. We can find from the pure technical efficiency that if the scale is invalid, even if the pure technical is efficiency, the overall technical efficiency will also result in invalid.

5 Enterprises are scale effective, which is 5 enterprises be in the constant returns to scale, accounting for $16.1 \%$ of the total number of samples; 8 enterprises are in increasing returns to scale, accounting for $25.8 \%$ of the total number of samples; 18 enterprises are in decreasing return to scale, accounting for $58.1 \%$ of the total number of samples. We can see that most of the enterprises be in the area of diminishing returns to scale.

\subsection{The analysis of input redundancy and output deficiency ratio}

The DEAP2.1 results show that a total of 18 enterprises are pure technical inefficiency. When pure technical efficiency is invalid, it will cause input redundancy or output insufficient. Namely the redundancy rate is closely related to the pure technical efficiency. In the invalid pure technical efficiency of the enterprises, 7 enterprises that is $38.9 \%$ of the total are insufficient of profits, 16 enterprises that is $88.9 \%$ of the total are insufficient of operating income growth rate, 11 enterprises that is $61.1 \%$ of the total have insufficient inventory turnover, 2 enterprises that is $11.1 \%$ of the total have $\mathrm{R} \& \mathrm{D}$ staff redundant, 5 enterprises that is $27.8 \%$ of the enterprises have total $\mathrm{R} \& \mathrm{D}$ expenditure redundancy.

Such as the fourth DMU, namely eastcom peace smart card Limited by Share Ltd, pure technical efficiency is 0.199 , mainly due to the normalized total profit rate deficiency is 0.001 , the normalized operating income growth rate is 0.293 , the inventory turnover rate is 0.410 , R \& D expenditure redundancy is 417.258.So enterprises must enhance the ability of independent innovation through $\mathrm{R} \& \mathrm{D}$, and then improve profitability and business development capacity and operating efficiency, improve the efficiency of research and development. The 23rd DMU, namely three-dimensional communications Limited by Share Ltd pure technical is invalid, mainly because 
the total profit and sales growth rate caused by insufficient investment in R \& D. It expresses that the effect is not obvious, resulting in insufficient output.

\section{3 the projection of DMU in the production frontier}

According to the DEA theory, the projection of DMU of ineffective DEA in the production frontier is DEA effective, namely by appropriately adjusting the non DEA effective DMU input, the output value can reach the DEA effectively.

We take DMU4, namely eastcom peace smart card Limited by Share Ltd as an example, the DEAP2.1 output results are shown as follows:

Results for firm: $\quad 4$
Technical efficiency $=0.199$
Scale efficiency $=0.914$
PROJECTION SUMMARY:

\begin{tabular}{lcrrrr}
\multicolumn{1}{c}{ variable } & \multicolumn{2}{c}{ original } & \multicolumn{2}{c}{ radial } & \multicolumn{2}{c}{ slack } & \multicolumn{2}{c}{$\begin{array}{c}\text { projected } \\
\text { molue }\end{array}$} \\
& value & \multicolumn{2}{c}{ movement } & movement & \multicolumn{1}{c}{ value } \\
output & 1 & 0.155 & 0.000 & 0.001 & 0.156 \\
output & 2 & 0.390 & 0.000 & 0.293 & 0.683 \\
output & 3 & 3.370 & 0.000 & 0.410 & 3.780 \\
input & 1 & 311.000 & -249.000 & 0.000 & 62.000 \\
input & 2 & 2869.000 & -2297.045 & -417.258 & 154.697
\end{tabular}

In order to achieve DEA effective, i.e.to make the total technical efficiency of the eastcom peace smart card Limited by Share Ltd to reach 1,we need to adjust the input data for R \& D personnel number: $\mathrm{X}_{1}=62$, the total $\mathrm{R}$ \& $\mathrm{D}$ expenditure $\mathrm{X}_{2}=154.697$ million. Output data is adjusted as following: The normalized total profit $\mathrm{y}_{1}=0.156$, the normalized total operating income growth rate $y_{2}=0.683$, inventory turnover rate $y_{3}=3.780$. In this way, data can reach the optimal value, DEA is effective, the overall efficiency is 1.

\section{Conclusion}

\subsection{The overall input of $R \& D$ in Listed SMEs is inadequate}

The scale and strength of $\mathrm{R} \& \mathrm{D}$ investment is an important index to measure the enterprise innovation ability. It is one of the main ways to form the core competitiveness of enterprises. In order to maintain its survival and development, enterprises should continue to carry out technological innovation. To improve the independent innovation of enterprises should base on the $\mathrm{R} \& \mathrm{D}$ activities. But we find that the small and medium-sized enterprises' investment in R \& D is inadequate at present as a result of the survey sample.

When the pure technical is inefficiency, it will cause redundant input or output deficiency. In the sample enterprises, 13 enterprises are efficient in pure technical, accounting for $41.9 \%$ of the total number of samples. The biggest cause of invalid pure technical efficiency is due to insufficient output. Only 2 enterprises are redundant in R \& D personnel, accounting for $8.5 \%$ of the total sample number. Only 5 enterprises are redundant in R \& D expenditure, accounting for $16.1 \%$ of the total sample. And the proportion of the total enterprises are $22.6 \%, 51.6 \%, 35.5 \%$ respectively with insufficient of total profit rate, operating income growth rate and inventory turnover rate. Therefore, the enterprise which is inadequate investment in R \& D should make an objective assessment of its technology innovation capacity, fully understand the great significance of the investment in research and development for the development of enterprises, change the concept and adjust the strategy, take research and development as the key to improve the innovation ability, maintain and develop core competitiveness.

\subsection{The R \& D scale efficiency of the listing of SMEs is not high}

There are 18 enterprises are in scale efficiency decreasing in sample enterprises.5 enterprises are in constant returns to scale, 8 enterprises are in increasing returns to scale. In the sample enterprise, 13 enterprises reach to pure technical efficiency (i.e. the efficiency of R \& D), accounting for $41.9 \%$ of the total number of samples, but only 5 enterprises achieve the total technical efficiency, 
accounted for $16.1 \%$. There are $25.8 \%$ (8) of the enterprises are invalid in the total technical efficiency caused by invalid in scale efficiency under the pure technical is efficient. Survey results show that the R \& D and the size of many small and medium enterprises do not match. For increasing returns to scale of the enterprise, it should further increase investment in research and development, enhance the strength of enterprises, to achieve the total technical efficiency. For diminishing returns to scale of the enterprises, the existing R \& D investment did not significantly improve the enterprise competition ability, it should take measures, reduce duplication of investment in research and development, and actively carry out cooperation with universities and research institutes, strengthen the cooperation between enterprises and exchanges of information. Let the development is more reasonable for the market and improve the efficiency of research and development.

\section{References}

[1] Cheng,H.W., Zhang,Y.H, Chang,Y. An Empirical Study on the Relationship Between R\&D Investment and Company Performance[J], Study On Management Science, 2006,3.

[2]Yu,X.C. An Empirical Study On The Relationship Between R \& D Investment and Output Growth in China [J], The Management Of Science And Technology, 2009,10.

[3] Xie, W.M., Tang,Q.Q., R \& D Investment Enterprises and the Actual Performance: Understanding A Shares Of Listing Corporation [J], Reform, 2011,3.

[4] Yu,N. Design Of R \& $\mathrm{D}$ Expenditure Performance Evaluation System Of Chinese[J] ,Commercial Era, 2006,2.

[5] Liang,L.X., Zhang,Y.B. R\&D Investment And Performance Status Of High-Tech Enterprises In Our Country And Analysis Of [J], Management Of Research And Development, 2006,1.

[6] Zhou,G.H, Lu,L.J. An Empirical Study on the Measurement of Enterprise R\&D Performance -Based on Survey And Analysis Of 1162 SMEs In Zhejiang Province [J], Management Of Agricultural Science And Technology, 2002,3.

[7] Zhu,W.P., Lun,R. Empirical Analysis Between High-Tech Investment and the Performance Of Science And Technology Enterprises [J], Science and Technology Management Research, 2004,5.

[8] You,C. An Empirical Study of the Relationship Between SMEs' R \& D Investment and Financial Performance -- Based On Panel Data From SME Board Of Listing Corporation in our Country [J], Southern Finance, 2010,1. 